\title{
Kajian Kuat Tekan Beton Menggunakan Pasir Quary Malanu Kampung Dengan Campuran Serat Aluminium Dan Logam
}

\author{
Wennie Mandela ${ }^{1}$, Achmad Rusdi ${ }^{2}$, Wish Man Silalahi ${ }^{3}$ \\ ${ }^{1,2}$ Dosen Program Studi Teknik Sipil Universitas Muhammadiyah Sorong \\ ${ }^{3}$ Mahasiswa Program Studi Teknik Sipil Universitas Muhammadiyah Sorong
}

\begin{abstract}
Abstrak
Beton merupakan suatu campuran homogeny yang terdiri dari agregat halus (pasir/abu batu) danb agregat kasar (kerikil/ batu pecah) dan bahan pengikat pasta yaitu semen+air, dengan perbandingan tertentu, dan dapat pula ditambahkan pula dengan campuran lainnya apabila dianggap perlu. Beton diminati karena mempunyai sifatsifat fisik dan karakter tertentu, dapat bervariasi sesuai dengan perubahan proporsi komponen material penyusunnya. Inovasi teknologi beton selalau dituntut guna menjawab tantangan tantangan akan kebutuhan, beton yanag dihasilkan diharapkan mempunyai kualitas tinggi meliputi kekuatan dan daya tahan tanpa mengabaikan nilai ekonomis, penambahan serat pada campuran beton meperlihatkan beberapa keuntungan potesial.Dalam penelitian ini serat yang digunakan adalah serat aluminium dan logam dan agregat dari PT. PII Kota Sorong dan Quary Malanu Kampung Jln F Kalasuat Kota Sorong Metode yang digunakan adalah metode penelitian eksperimental dengan cara membuat benda uji di Laboratorium Universitas Muhammadiyah Kota Sorong. Hasil yang diperoleh, hasil yang diperoleh, penambahan serat aluminium dan logam pada campuran beton normal mengalami penurunan kekutan beton dibandingkan serat aluminium dan logam. Semakin besar kadar penambahan serat aluminium dan logam yang di berikan maka kekuatan beton tersebut akan semakin menurun. Kuat tekan rata-rata hari ke 28 untuk beton normal $33.781 \mathrm{Mpa}$, pada serat aluminium dan logam $2 \%$ mengalami penurunan kuat tekan sebesar $60.895 \%$ dan serat aluminum dan logam $4 \%$ mengalami penurunan $60.339 \%$.
\end{abstract}

Kata kunci : beton, agregat, serat aluminium, kuat tekan

\section{Pendahuluan}

Pada saat ini perkembangan di bidang konstruksi bangunan mengalami kemajuan yang pesat. Dengan semakin pesatnya pertumbuhan pengetahuan dan teknologi di bidang konstruksi mendorong untuk lebih memperhatikan standar mutu serta produktivitas kerja. Teknologi di bidang konstruksi dapat berperan serta dalam meningkatkan sebuah pembangunan konstruksi dengan lebih berkualitas (Saputro, 2017).

Hal ini membuat para investor bekerja sama dengan pelaku konstruksi dalam berusaha untuk menjawab tantangan tersebut. Beton merupakan konstruksi yang sudah tidak asing lagi dalam bidang teknik sipil, hampir setiap bangunan sipil baik itu gedung, jembatan, maupun banguna air menggunakan beton sebagai struktur utama maupun srtuktur pelengkap. Suatu srtuktur beton terdiri dari elemen - elemen yang membentuk satu kesatuan struktur. Elemen- elemen struktur terdiri dari pondasi, kolom, balok, plat lantai, dan lain-lain

Selama ini telah diketahui bahwa beton memiliki berbagai kelebihan sebagai bahan konstruksi dibandingkan dengan bahan yang lain. Salah satu kelebihannya yaitu bahwa bahan pembentuk beton dapat diperoleh dengan mudah baik secara alami atau dicari alternative bahan lain, pada penelitian ini digunakan bahan alternatif, sehingga bahan relative murah yang artinya dapat ditemukan di tempat-tempat sampah (kaleng-kaleng aluminium bekas) namun mudah dalam pengerjaannya dan dapat di bentuk sesuai dengan keinginan, tahan terhadap cuaca serta perawatan bangunan yang relatif murah. Bahan tambah Serat Aluminium adalah bahan-bahan yang ditambahkan ke dalam campuran beton pada saat atau selama pencampuran beton berlangsung. Fungsi bahan ini adalah mengubah sifat-sifat beton agar menjadi lebih cocok untuk pekerjaan tertentu,atau untuk menghemat biaya. Menurut, (Spesifikasi Bahan Tambahan untuk Beton, SK SNI S-18-1990-03). Serat Aluminium didefinisikan sebagai material selain air, agregat dan semen hidrolik yang dicampur dengan beton atau mortar yang ditambahkan sebelum atau selama pengadukan berlangsung. Bahan tambah 
digunakan untuk memodifikasi sifat dan karakteristik dari beton misalnya untuk kemudahan pengerjaan atau untuk lain yaitu penghematan energi.

Di Indonesia bahan tambah telah banyak digunakan. Namun bahan tambah yang digunakan harus memenuhi ketentuan yang diberikan. Dalam penelitian ini menggunakan pasir dari Quary Malanu Kampung karena banyak orang beranggapan bahwa pasir yang berasal dari Quary Malanu Kampung berwarna kuning yang berarti banyak mengandung lumpur, Jika dalam agregat mengandung lumpur maka akan menambah permukaan agregat sehingga keperluan air untuk membasahi semua permukaan butiran dalam campuran meningkat. Ini mengakibatkan kekuatan dan ketahanan beton dapat menurun Karena pengaruh buruk tersebut. Adapun tujuan penelitian ini sebagai berikut:

1. Untuk mengetahui pengaruh penambahan Serat Aluminium dan logam terhadap sifat fisik dan mekanik kuat tekan beton normal setelah mendapatkan perawatan.

2. Untuk mengetahui mutu beton normal dengan perbedaan kekuatan mutu beton setelah mendapat bahan tambah serat aluminium dan logam

\section{Metode Penelitian}

2.1. Lokasi Penelitian

Lokasi penelitian ini dilakukan di Jln Pendidikan Universitas Muhammadiyah Sorong (UMS), Papua Barat.

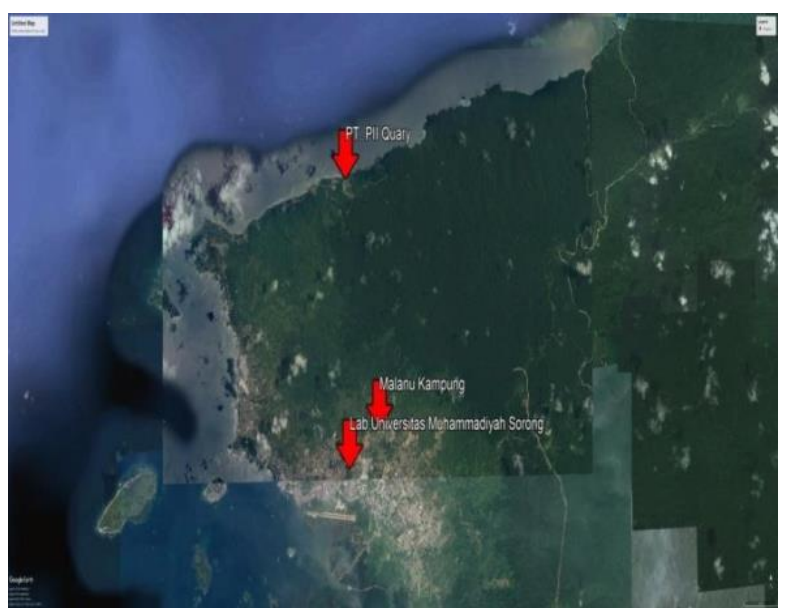

Gambar 1. Lokasi Penelitian

Sumber : Google earth

\subsection{Tahapan Penelitian}

1. Tahap Persiapan

Pada tahap persiapan ini meliputi :

a. Studi pustaka terhadap materi untuk proses analisa

b. Menemukan kebutuhan data

c. Mendata dan membuat sampel beton agar mendapat perbandingan.

2. Tahap Pengumpulan Data

Pengumpulan data merupakan langkah awal setelah tahap persiapan dalam proses pelaksanaan yang sangat penting, karena dapat ditentukan permasalahan dan rangkaian penetuan alternatif pemecahan masalah yang akan diambil. Adapun beberapa metode yang dilakukan dalam tahap pengumpulan data ini antara lain :

a. Data Primer

Data primer adalah data yang langsung diambil dari lapangan, meliputi observasi, : Pengambilan material-material dari Quary diskusi terfokus serta, pembuatan sampel beton yang di lakukan di laboratorium.

b. Data Sekunder

Data sekunder adalah data yang diperoleh atau dikumpulkan peneliti dari berbagai sumber yang telah ada (peneliti sebagai tangan kedua). Data sekunder dapat diperoleh dari berbagai sumber seperti departemen pekerjaan umum, penelitianpenelitian terdahulu, buku, laporan, jurnal, dan lain-lain. Untuk lebih jelasnya bisa di liat pada diagram alir penelitian (flow chart) seperti gambar di bawah ini 


\subsection{Diagram Alir Penelitian}

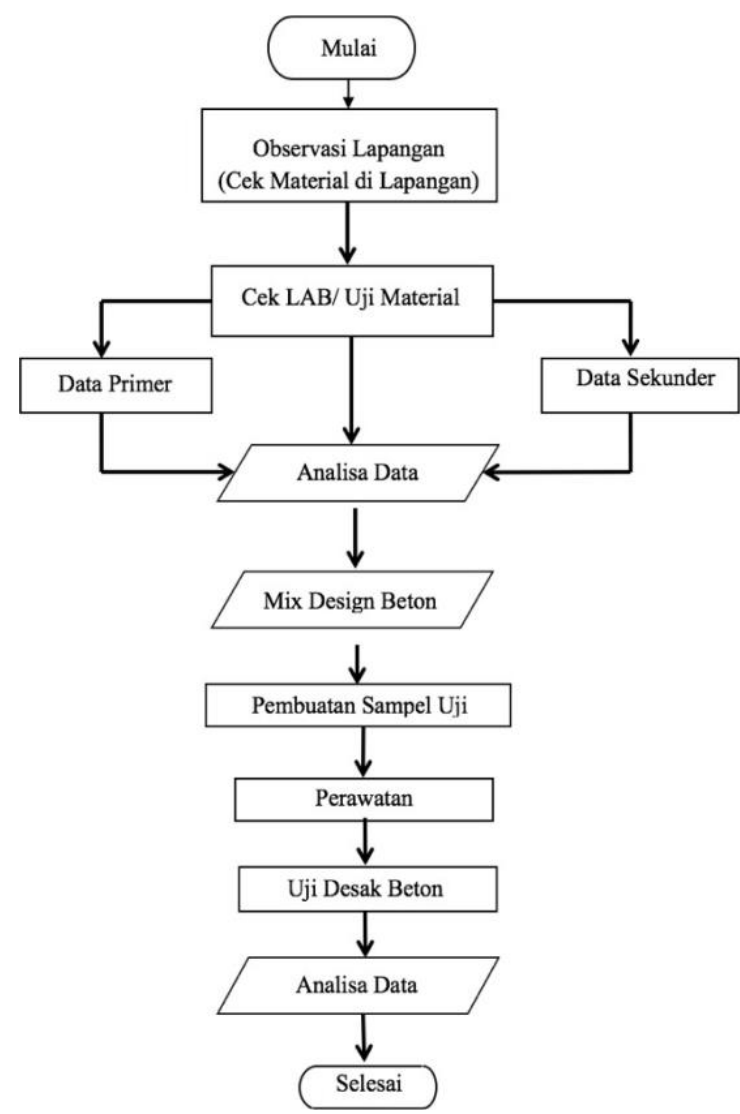

Gambar 2. Flow Chart

\subsection{Teknik Pengambilan Data}

Data didapatkan dengan melakukan Penelitian di laboratorium, di mana peneliti secara langsung melakukan, mengamati, serta mengevaluasi sampel beton. Dari penelitian ini, maka peneliti juga akan melihat a pakah beton serat tersebut telah memenuhi ketentuanketentuan untuk layak digunakan atau tidak. Prinsip penambahan serat adalah memberi tulangan pada beton yang disebar merata ke dalam adukan beton agar tidak terjadi retakanretakan yang terlalu dini (Soroushian dan Bayasi, 1987) mempertimbangkan dari data tersebut, maka peneliti dapat mengevaluasi bagaimana Beton yang di hasilkan dengan tambahan serat aluminium dan logam.

\section{Hasil dan Pembahasan}

Hasil evaluasi beton tambahan serat aluminium dan logam

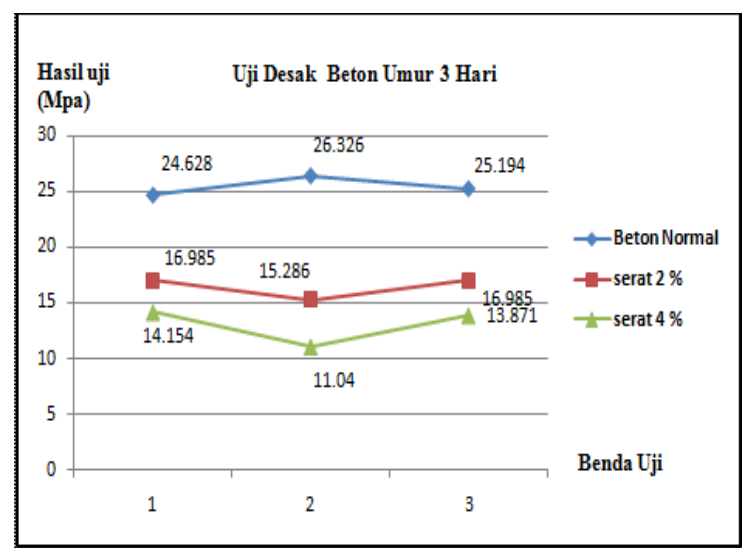

Gambar 3. Hasil uji tekan umur 3 hari Sumber : Hasil penelitian

Untuk beton dengan penambahan serat Aluminium dan logam terhadap beton normal sebesar $2 \%$ dan $4 \%$ mengalami persentase penurunan yakni $2 \%$ sebesar $35,316 \%$. Dan $4 \%$ sebesar $48.7 \%$ dari mutu beton normal dengan. perhitungan sebagai berikut:

$$
\begin{array}{ll}
(16,418 / 25,382) \times 100 & =64,684 \\
100 \%-64,684 \% & =35,316 \% \\
(13,021 / 25,382) \times 100= & 51,300 \\
100 \%-51,300 \% & =48,7 \% .
\end{array}
$$

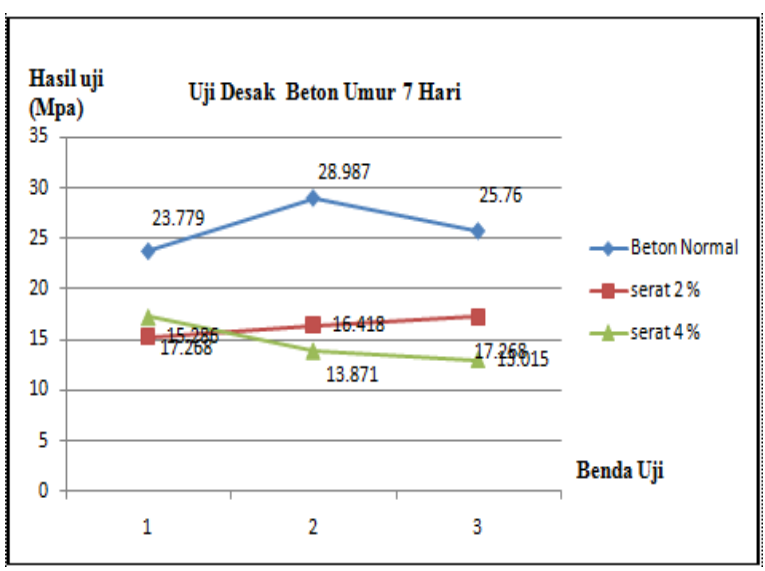

Gambar 4. Hasil uji tekan umur 7 hari Sumber : Hasil penelitian 
Untuk beton dengan penambahan serat Aluminium terhadap beton normal sebesar $2 \%$ dan $4 \%$ mengalami persentase penurunan yakni $2 \%$ sebesar $37.636 \%$ dan $4 \%$ sebesar $40,161 \%$ dari mutu beton normal dengan perhitungan sebagai berikut:

$$
\begin{array}{cc}
(16,324 / 26,175) \times 100=62,364 \\
100 \%-62,364 \% \quad=37,636 \% . \\
(15,663 / 26,175) \times 100=59,839 \\
100 \%-59,839 \% \quad=40,161 \%
\end{array}
$$

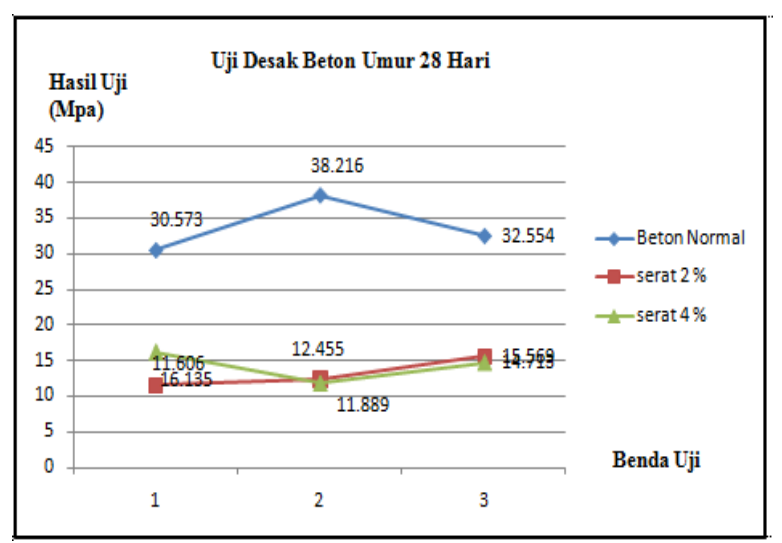

Gambar 5. Hasil uji tekan umur 28 hari (Sumber : Hasil penelitian )

Untuk beton dengan penambahan serat aluminium terhadap beton normal sebesar $2 \%$ dan $4 \%$ untuk 28 hari mengalami persentase penurunan. yakni $2 \%$ sebesar $60,895 \%$ dan $4 \%$ sebesar 60,339 dari mutu beton normal dengan perhitungan sebagai berikut:

$$
\begin{aligned}
& (13,210 / 33,781) \times 100=39,105 \\
& 100 \%-39,105 \%=60,895 \% \\
& (13,398 / 33,781) \times 100=39,661 \\
& 100 \%-39,661 \%=60,339 \%
\end{aligned}
$$

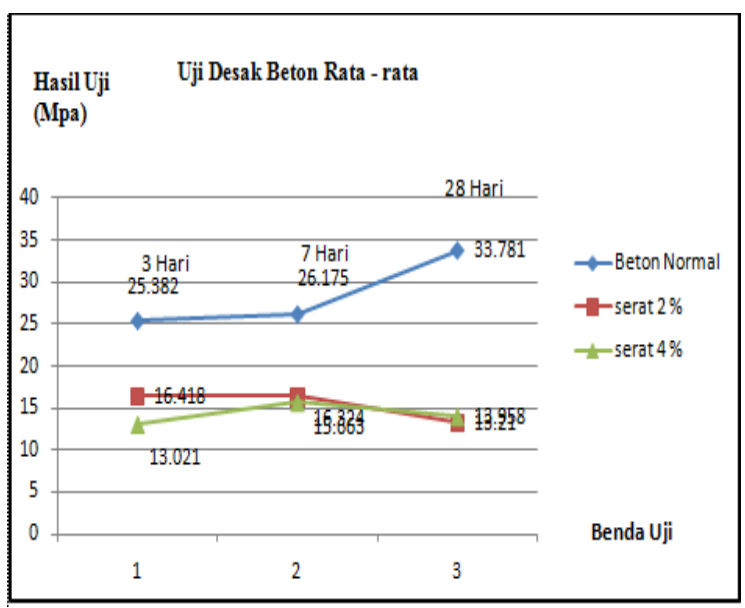

Gambar 6. Hasil uji tekan rata-rata). Sumber : Hasil Penelitian
Setelah melihat hasil uji tekan, ternyata kuat tekan yang direncanakan yakni sebesar $25 \mathrm{Mpa}$ tercapai pada beton normal sebesar 33,781 Mpa, sedangkan pada beton hasil penambahan serat aluminium 2\% setelah dirata-ratakan sebesar 16,418 Mpa dan Untuk penambahan serat aluminium sebesar $4 \%$ setelah dirata-ratakan sebesar 15,663 Mpa, kekuatan pada beton dengan penambahan serat aluminium terhadap beton normal tentunya mengalami penurunan, semakin besar penambahan serat Aluminium, maka semakin menurun kualitas beton yang dihasilkan

\section{Kesimpulan}

Berdasarkan pada hasil penelitian dan pembahasan yang telah di uraikan sebelumnya dapat diperoleh beberapa kesimpulan sebagai berikut ini.

1. Pengaruh kekuatan mutu beton normal dengan penambahan serat aluminium memberikan konstribusi yang kurang baik terhadap beton dimana dengan penambahan serat aluminium yang lebih besar maka semakin menurunkan kualitas beton yang dihasilkan.

2. Perbedaan persen kuat tekan beton normal dan beton yang menggunakan serat aluminium mengalami penurunan kuat tekan pada beton, persentase penurunan untuk beton berumur 3 hari adalah 35,316\% (untuk tambahan serat aluminium $2 \%$ ). $48,7 \%$ (untuk tambahan serat aluminium 4 $\%$ ) sedangkan 7 hari adalah 37,636\% (untuk tambahan serat aluminum 2\%) $40,161 \%$ (untuk tambahan serat aluminium 4\%). dan pada beton berumur 28 hari mengalami penurunan kuat tekan pada beton sebesar 60,895\% (untuk tambahan serat aluminium 2\%). 60,339\% (untuk tambahan serat aluminium 4\%).

\section{Referensi}

Antono, Achmad, 1985, Bahan Konstruksi Teknik Sipil I-IV, Diktat Fakultas Teknik Universitas Gajah Mada, Yogyakarta.

ASTM, 1995, Concrete and Agregates, Annual Book of ASTM Standart, Vo. 04. 02. 1995, Philadelphia.

Departemen Pekerjaan Umum, LPMB. 1971. Peraturan Beton Bertulang Indonesia 1971. Yayasan Lembaga Penyelidikan Masalah Bangunan, Bandung. 
Departemen Pekerjaan Umum, LPMB. 1991.

Tata Cara Rencana Pembuatan Campuran

Beton Normal. SK SNI ,03-2834-2000.

Yayasan Lembaga Penyelidikan Masalah Bangunan, Bandung.

Dipohusodo, Istimawan, 1996, Struktur Beton Bertulang, PT Gramedia Pustaka Utama, Jakarta

Saputro, I. T. (2017). FORMULASI PROPORSI STYROFOAM TERHADAP PASIR MERAPI DAN PENGARUHNYA PADA KUAT TEKAN DAN KUAT LENTUR BATAKO RINGAN. RANCANG BANGUN, 3(1).

SK SNI S-18-1990-03S pesifikasi Bahan Tambahan untuk Beton,

Soroushian dan Bayasi, (1987) Memberi tulangan pada beton agar tidak terjadi retakan dini. 